\title{
Anti-Obesity Effects of Aloe Vera Whole Leaf and Sitagliptin in Diabetic Rats
}

\author{
Sobia Javaid ${ }^{1}$, Akbar Waheed ${ }^{2}$
}

\begin{abstract}
PGT, MPhil Pharmacology, Islamic International Medical College, Rawalpindi Pakistan
1 Conception of study, Designing, Planning experimentation, Study conduction, Analysis, interpretation, Discussion, Manuscript writing, Procurement for reagents, Material analysis and bearing all expenses of study

2 Professor \& Head, Department of Pharmacology, Islamic International Medical College, Rawalpindi Pakistan

Supervised the whole study, Critical review

\author{
Submitted for Publication: $x x-x x-20 x$ \\ Accepted for Publication $x x-x x-20 x$ \\ CORRESPONDING AUTHOR \\ Dr. Sobia Javaid \\ PGT, MPhil Pharmacology, Islamic International \\ Medical College, Rawalpindi Pakistan \\ Email:drsobiaqazi@gmail.com
}

\section{ABSTRACT}

Background: Aloe Vera, a medicinal herb, has been used for centuries in therapeutics and cosmetology. Objective: To compare Antiobesity effects of Aloe Vera whole leaf with new antidiabetic drug, Sitagliptin on streptozotcin induced diabetic rats. Study Design: Randomized Control Trial. Settings: Department of Pharmacology, Islamic International Medical College, Rawalpindi in collaboration with NIH, Islamabad, Pakistan. Duration: One year from September 2019 to August 2020. Methodology: Young Sprague Dawley rats, $n=40$, weighing 220-250 grams were taken and randomly divided into Groups A and B. Group B was fed on high fat diet for two weeks to develop insulin resistance. After induction of diabetes, with low dose streptozotocin, Group B was subdivided into: GroupB1 (Diabetic Control), Group B2 (Aloe Vera whole Leaf treated), Group B3 (Sitagliptin treated). Body weight was measured in all rats every week to assess progress of study, and finally on completion of study (on Day 60). SPSS version 25 was applied for statistical analysis. One-way ANOVA test was used for assessing any difference in the mean values. Post-hoc Turkey analysis was done to compare inter-group mean differences. P value of $<0.05$ was considered significant. Results: Mean body weight of Group A was 235.50g, Group B1 $272.00 \mathrm{~g}$, B2 249.90g and B3 248.70g respectively. Rats in each of Group B2 and Group B3 had significant reduction in body weight compared to Group B1, with no statistically significant intergroup differences in results of Group B2 and B3. Conclusion: Aloe Vera whole leaf extract significantly decreased body weight with almost similar efficacy to Sitagliptin in diabetic rats.

Keywords: Aloe Vera, Hypoglycemic agents, Sitagliptin, Streptozotocin.

How to Cite: Javaid S, Waheed A. Anti-Obesity Effects of Aloe Vera Whole Leaf and Sitagliptin in Diabetic Rats. APMC 2020;14(4):295-8. DOI: $10.29054 / \mathrm{APMC} / 2020.1023$

\section{INTRODUCTION}

Obesity and type 2 diabetes mellitus are conjoint, emergent, and unified health issues of today's world. According to World Health Organization (WHO) estimates, near about 171 million people are suffering from diabetes worldwide, with 82 million diabetics, clustered in the South East Asian regions. ${ }^{1}$ Obesity, endorses insulin resistance and accounts for $80 \%$ of the population-attributable risk for developing type 2 diabetes mellitus. ${ }^{2}$ Unluckily, various existing therapies for type 2 diabetes, particularly sulphonylureas, thiazolidinediones and insulin, result in weight gain and may intensify the adverse effects of Visceral adipose tissues (VAT) in patients with type 2 diabetes mellitus. ${ }^{3,4}$ Although lifestyle changes lead to early weight loss, weight regain is common. Consequently, clinical strategies for consistent weight loss remain unmet needs of type 2 diabetes management. ${ }^{4}$

Orally administered dipeptidy-1 peptidase-IV (DPP-IV) inhibitors have emerged as a new class of oral hypoglycemic agents with the potential of enhancing the biological effects of incretin hormones via inhibiting their inactivation by dipeptidy-1 peptidase- 4 enzyme. ${ }^{5}$ Sitagliptin, the $1^{\text {st }}$ orally available DPP-IV inhibitor, developed in 2006, is successfully being used for better glycemic control in a broad range of patients with type 2 diabetes, including obese, elderly and those with deranged cardiovascular and kidney profile. ${ }^{6}$ The enzyme dipeptidy-l peptidase-4 (DPP-4) is expressed in various tissues including visceral adipose tissue and promotes adipogenesis .Sitagliptin, with its DPP-4 inhibitory activity, abolishes fat proliferation and markedly diminishes visceral adiposity in obese type 2 diabetic patients. ${ }^{7}$ It helps in maintaining body weight via delayed gastric emptying; decreased fat absorption from the GIT; increased lipid break down in adipose tissue along with increased oxidation of fatty acids in skeletal muscles. ${ }^{8}$

Aloe Barbadensis Miller (Aloe Vera), a member of the genus Aloe, is a kind of traditional medicinal plant belonging to the family Liliaceous. ${ }^{9}$ It is a semitropical to tropical, perennial succulent xerophyte, with water storage tissues in leaves to pull through dry conditions and places with low rainfall. Aloe Vera is given the title "Pharmacy of 
Nature" because of its multiple magical wonders in therapeutics since pre-biblical times. ${ }^{10}$ Nowadays, it is successfully being used for regulating blood glucose levels in diabetic patients because of the complex interplay of its numerous biologically active ingredients. Further, its hypoglycemic property is often linked to pancreatic insulin synthesis and release. ${ }^{11}$ In present study, comparative antiobesity effects of Aloe Vera whole leaf extract with standard antidiabetic drug, Sitagliptin were observed. As far as we know, no comparative studies on antiobesity effects of Aloe Vera whole leaf with sitagliptin are done till date.

\section{METHODOLOGY}

Study Design: Randomized Control Trial.

Settings: Pharmacology Department of Islamic International Medical College, Rawalpindi in collaboration with National Institute of Health (NIH), Islamabad Pakistan.

Duration: One year from September 2019 to August 2020. Sample Size: 40 male albino rats.

Inclusion Criteria: Male albino rats of body weight 220250 grams.

Exclusion Criteria: Female albino rats and rats below 220 grams.

Data Collection Procedure: 2 months old, healthy adult Sprague Dawley rats, of 220-250 g weight were procured from animal house of NIH and housed in standard cages under standard laboratory conditions. Ten rats received normal standard diet and the remaining thirty rats received high fat standard diet (protein $=20 \%$, carbohydrates $=20 \%$, lipids $=60 \%$ ), prepared at $\mathrm{NIH}$ as standard food pellets according to the recommendations approved by the universities federation for animal welfare. ${ }^{12}$ The care and handling of subjects was in harmony with the internationally accepted standard guidelines of use of animals. After 1 week of acclimatization, the rats were randomly distributed into two main groups; 10 rats in group A and the remaining (30) in experimental group B. Group A was labelled as Normal Control and took normal saline and normal standard diet while the Group B received high fat standard diet for two weeks. Rats in group B were found to have significant increase in body weight after two weeks of dietary manipulations. Streptozotocin catalogue number 4191002-1(714986), CAS No. 18883-66-4, Brand bio world USA, bought from commercial supplier was set just before use and injected within 5 min of dissolution in citrate buffer. ${ }^{13}$ Overnight fasted rats were given single intra-peritoneal injection of streptozotocin at the dose of $35 \mathrm{mg} / \mathrm{kg}$ body weight. Fasting blood glucose was recorded, after 3 days of streptozotocin administration to confirm diabetes. Rats with fasting blood glucose equal and above $250 \mathrm{mg} / \mathrm{dl}$ were considered diabetic.

Research grade Sitagliptin, Batch No: M-20191010-D05M06-01, supplied by CCL Pharmaceuticals, Lahore,
Pakistan and given orally at dose of $10 \mathrm{mg} / \mathrm{kg}$ body weight/day for 40 days. ${ }^{14}$ Fresh, 2 -3 years old, healthy Aloe Vera brought from local nursery and plant material identification was done by Herbarium of PakistanQuaid-e-Azam University Islamabad, Department of Plant Sciences. Accession Number is 132644 and Voucher Specimen Number 125, preserved at their Herbarium. Aloe Vera leaves were thoroughly washed under tap water, thorny edges were removed along with the yellow sap. Thin slices of the whole leaf were made and put for 5 days in sun to get dried..$^{15}$ The leaf powder was made after grinding them carefully, and stored in a tightly closed glass jar, under cool, dry and dark conditions and later given orally to rats, mixed in feed (food pellets), at calculated dose $\left(300 \mathrm{mg} / \mathrm{kg}\right.$ body weight/day), ${ }^{16}$ for 40 days. Body weight was checked every week to assess progress of study and finally on completion of study at Day 60. For body weight measurement, triple beam laboratory animal weighing balance was used.

Data Analysis: Statistical analysis was done by applying the statistical package for Social Sciences version 25 (SPSS 25). Results were documented as mean +_SEM. Comparisons of quantitative parameters among the four groups were analyzed by using one-way ANOVA (post hoc turkey test). P-value of less than 0.05 was considered as significant.

\section{RESULTS}

At the start of study (Day Zero), body weights were comparable to each other in all groups. After two weeks of HFD, significant increase in body weight of group B rats was seen. On administration of Streptozotocin single $\mathrm{I} / \mathrm{P}$ injection at a low dose of $35 \mathrm{mg} / \mathrm{kg}$, diabetes was successfully induced in group $B$ rats. Treatment was started in Group B2 (Aloe Vera whole leaf) and Group B3 (Sitagliptin). Body weight was checked every week in all rats. After completion of study, at day 60, Mean body weight of Group A was 235.50g, Group B1 272.00g, B2 $249.90 \mathrm{~g}$ and B3 $248.70 \mathrm{~g}$ respectively. Rats in each of Group B2 (Aloe Vera whole leaf treated) and Group B3 (Sitagliptin treated) had significant reduction in body weight in comparison to the Group B1 (diabetic control), $P$ value $<0.001$, with no statistically significant intergroup differences among B2 and B3, P value $>0.05$.

Table 1: Comparison of mean value + SEM (standard error of mean) of mean weight (g) of all groups on day $60(n=40)$

\begin{tabular}{|c|c|c|c|c|}
\hline Groups & $\begin{array}{c}\text { Group } \\
\text { A } \\
\text { control }\end{array}$ & $\begin{array}{c}\text { Group B1 } \\
\text { disease } \\
\text { control }\end{array}$ & $\begin{array}{c}\text { Group B2 } \\
\text { Aloe Vera } \\
\text { leaf }\end{array}$ & $\begin{array}{c}\text { Group B3 } \\
\text { Sitaglipti } \\
\text { n }\end{array}$ \\
\hline Mean & 235.50 & 272.00 & 249.90 & 248.70 \\
\hline SEM & 2.49 & 0.87 & 0.31 & 0.34 \\
\hline P Value & \multicolumn{4}{|c|}{$<0.001^{*}$} \\
\hline
\end{tabular}


Table 2: Comparison of mean + SEM (standard error of mean) of weight $(g)$ of all groups on day $60(n=40)$

\begin{tabular}{|c|c|c|}
\hline Groups & Mean Difference & P Value \\
\hline A vs B1 & $36.50 \pm 1.71$ & $<0.001^{*}$ \\
\hline A vs B2 & $14.40 \pm 1.71$ & $<0.001^{*}$ \\
\hline A vs B3 & $13.20 \pm 1.71$ & $<0.001^{*}$ \\
\hline B1 vs B2 & $22.10 \pm 1.71$ & $<0.001^{*}$ \\
\hline B1 vs B3 & $23.30 \pm 1.71$ & $<0.001^{*}$ \\
\hline B2 vs B3 & $1.20 \pm 1.71$ & 0.955 \\
\hline
\end{tabular}

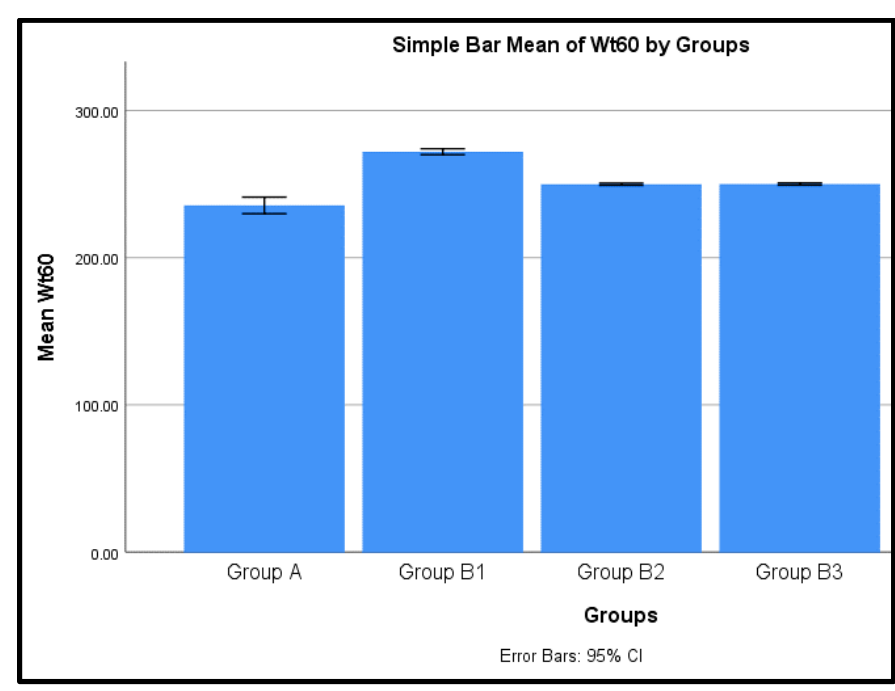

Figure 1: Graphical representation of mean of mena weight $(\mathrm{g})$ in groups on day $60(n=40)$

\section{DISCUSSION}

High fat diet with streptozotocin for type2 diabetes induction (HFD-STZ-T2D model) was used in present study. Since high-fat diet fed animals developed peripheral insulin resistance, so, animal models integrating a high fat diet, followed by low dose STZ to target the pancreatic $\beta$-cells would meticulously mimic the phenotype and the pathogenesis of human type 2 diabetes mellitus. ${ }^{17}$ Rahoui Walid et al investigated the anti-obesity effects of Aloe Vera administration at 100 and $200 \mathrm{mg} / \mathrm{kg} /$ day, in a diet-induced obesity rat model and found that Aloe Vera induced a significant decrease in body weight, food intake and relative adipose tissue weight in obese rats at both the doses along with a significant decrease in plasma-glucose, triglyceride and cholesterol levels. ${ }^{18}$ Results of this study are similar to Day 60 findings in present work where we observed significant decrease in body weight with Aloe Vera whole leaf extract treatment of diabetic rats of Group B2, compared to Diabetic Control Group B1who received normal saline.

Zahra Shakib et al reviewed the use of Aloe Vera in treatment of metabolic syndrome by different researchers and reported that the Aloe Vera extract might decrease plasma lipids through stabilization of saturated fatty acids, presumably via the scavenging of free radicals and regulation of lipid metabolism. ${ }^{19}$

Asuka Tada et al investigated the mechanism of antiobesity effects of Aloe Vera extract containing Aloe sterols on six weeks old high fed diet fed male mice. They found that Aloe Vera extract administration to rats for 11 weeks resulted in suppression of body weight gain and prevented obesity without altering food intake. They reported that oral intake of Aloe Vera extract caused upregulation of mRNA expression levels of genes related to brown adipose tissue activation which produces heat from burning of blood glucose and fat and stores energy in a smaller space compared to white fat, mechanism behind Aloe Vera's antiobesity effects. ${ }^{20}$

\section{CONCLUSION}

Aloe Vera whole leaf extract and Sitagliptin significantly lowered body weight in HFD-STZ - T2DM rat model and both treatments had almost similar efficacy with minor statistically insignificant differences $(P$ value $>0.05)$ in controlling metabolic changes in HFD-STZ - T2DM rat model. Therefore, both Aloe Vera whole leaf extract and sitagliptin can be used interchangeably in treatment of obesity in type 2 diabetes mellitus. This will help obese diabetic patients to regulate body weight through safe and cost effective mans.

\section{LIMITATIONS}

Owing to time constrains, cost and availability issues mRNA expression levels in the experimental Rat's liver and other tissues was not done.

\section{SUGGESTIONS / RECOMMENDATIONS}

Combined effects of Aloe Vera extract with sitagliptin should be explored.

\section{CONFLICT OF INTEREST / DISCLOSURE}

None to declare.

\section{ACKNOWLEDGEMENTS}

We acknowledge Animal house department of National Institute of health (NIH), Islamabad for their cooperation in animal care and handling.

\section{REFERENCES}

1. Dallumal RM, Chua SS, Wu DBC, Vethakkan SR. Sitagliptin: Is it effective in routine clinical practice? Int J Endocrinol. 2015;2015.950571.

2. Costanzo P, Cleland JGF, Pellicori P, Clark AL, Hepburn D, Kilpatrick ES, et al. The obesity paradox in type 2 diabetes mellitus: Relationship of body mass index to prognosis a cohort study. Ann Intern Med. 2015;162(9):610-8.

3. Neeland IJ, McGuire DK, Chilton R, Crowe S, Lund SS, Woerle HJ, et al. Empagliflozin reduces body weight and indices of adipose distribution in patients with type 2 diabetes mellitus. Diabetes Vasc Dis Res. 2016;13(2):119-26.

4. Cefalu WT, Stenlöf K, Leiter LA, Wilding JPH, Blonde L, Polidori $\mathrm{D}$, et al. Effects of canagliflozin on body weight and relationship to 
$\mathrm{HbA1c}$ and blood pressure changes in patients with type 2 diabetes. Diabetologia. 2015;58(6):1183-7.

5. Amritha CA, Kumaravelu P, Darling Chellathai D. Evaluation of anti-cancer effects of DPP-4 inhibitors in colon cancer-an invitro study. J Clin Diagnostic Res. 2015;9(12):14-6.

6. Scott LJ. Sitagliptin: A Review in Type 2 Diabetes. Drugs [Internet]. 2017;77(2):209-24. Available from: https://doi.org/10.1007/s40265-016-0686-9

7. Lima-Martínez MM, Paoli M, Rodney M, Balladares N, Contreras M, D'Marco L, et al. Effect of sitagliptin on epicardial fat thickness in subjects with type 2 diabetes and obesity: a pilot study. Endocrine. 2016;51(3):448-55.

8. Ferjan S, Janez A, Jensterle M. DPP4 inhibitor sitagliptin as a potential treatment option in metformin-intolerant obese women with polycystic ovary syndrome: A pilot randomized study. Endocr Pract. 2018;24(1):69-77.

9. Arunkumar S, Muthuselvam M. Analysis of phytochemical constituents and antimicrobial activities of Aloe vera L. against clinical pathogens. World J Agric Sci. 2009;5(5):572-6.

10. Dwivedi M. In Vitro Inhibition of Tinea Corporis from Various Extracts of Aloe vera and Azadirachta indica. Acta Scientific Microbiology. 2018;1(9):15-23.

11. Patel DK, Prasad SK, Kumar R, Hemalatha S. An overview on antidiabetic medicinal plants having insulin mimetic property. Asian Pac J Trop Biomed. 2012;2(4):320-30.

12. A O, Gul M, Moazzam S, Adil I. Effect of Aloevera Whole Leaf Extract in Combination with Rosiglitazone on Oxidative Stress and
Lipid Profile Levels in Type-2 Diabetic Rats. J Islam Med Dent Coll. 2018;7(3):159-64.

13. Furman BL. Streptozotocin-Induced Diabetic Models in Mice and Rats. Curr Protoc Pharmacol. 2015;70:5.47.1-5.47.20.

14. Reis F, Ferreira L, Teixeira-De-Lemos E, Pinto F, Parada B, Mega C, et al. Effects of sitagliptin treatment on dysmetabolism, inflammation, and oxidative stress in an animal model of type 2 diabetes (ZDF rat). Mediators Inflamm. 2010;2010.592760.

15. Pattali G, Yenge G, Cheluvadi R, Nidoni U, Hiregoudar S. Mathematical modeling for drying of whole leaf Aloe vera (Aloe barbadensis Miller). Agric Eng. 2015;40(2):41-8.

16. Althwab SA. Anti-diabetic Activity of Aloe vera Supplement Review. 2018;11(1):75-81.

17. Gheibi S, Kashfi K, Ghasemi A. A practical guide for induction of type-2 diabetes in rat: Incorporating a high-fat diet and streptozotocin. Biomed Pharmacother. 2017;95:605-13.

18. Rahoui W, Merzouk H, El Haci IA, Bettioui R, Azzi R, Benali M. Beneficial effects of Aloe vera gel on lipid profile, lipase activities and oxidant/antioxidant status in obese rats. J Funct Foods. 2018;48:525-32.

19. Shakib Z, Shahraki N, Razavi BM, Hosseinzadeh H. Aloe vera as an herbal medicine in the treatment of metabolic syndrome: A review. Phyther Res. 2019;33(10):2649-60.

20. Tada A, Misawa E, Tanaka M, Saito M, Nabeshima K, Yamauchi K, et al. Investigating Anti-Obesity Effects by Oral Administration of Aloe vera Gel Extract (AVGE): Possible Involvement in Activation of Brown Adipose Tissue (BAT). J Nutr Sci Vitaminol (Tokyo). 2020;66(2):176-84. 